Portland State University

PDXScholar

6-29-1989

\title{
Communication and Socialization Skills of Three Year Olds with a History of Language Delay
}

\author{
Pamela Susan Dahm \\ Portland State University
}

Follow this and additional works at: https://pdxscholar.library.pdx.edu/open_access_etds

Part of the Interpersonal and Small Group Communication Commons, and the Speech and Hearing Science Commons

Let us know how access to this document benefits you.

\section{Recommended Citation}

Dahm, Pamela Susan, "Communication and Socialization Skills of Three Year Olds with a History of Language Delay" (1989). Dissertations and Theses. Paper 3868.

https://doi.org/10.15760/etd.5752

This Thesis is brought to you for free and open access. It has been accepted for inclusion in Dissertations and Theses by an authorized administrator of PDXScholar. Please contact us if we can make this document more accessible: pdxscholar@pdx.edu. 
AN ABSTRACT OF THE THESIS OF Pamela Susan Dahm for the Masters of Science in Speech and Hearing Sciences presented June $29,1989$.

Title: Communication and socialization skills of Three Year olds with a History of Language Delay.

APPROVED BY MEMBERS OF THE THESIS COMMITTEE:
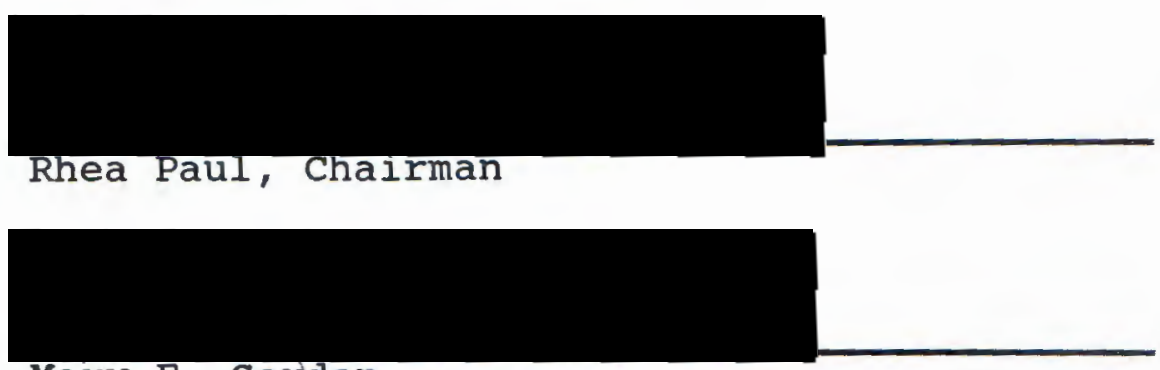
Mary E. Gordon

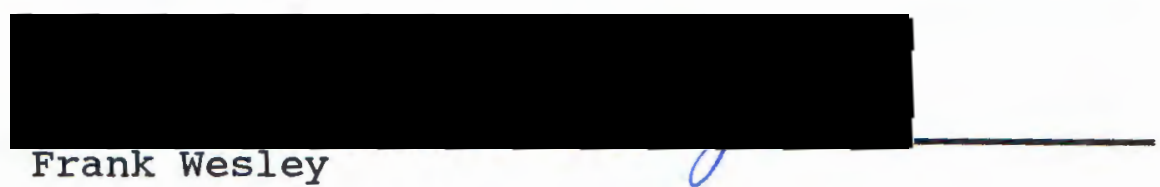

The purpose of this study was to compare receptive language, expressive language, and socialization skills of preschool children who have a history of expressive language delay (ELD) with age mates who have a history of normal language development.

54 preschoolers between the ages of 36 to 46 months were the subjects of this investigation. The subjects were involved in an ongoing study and were divided into two groups according to their normal or delayed language status 
at two years of age. The communication and socialization skills of each subject were measured according to the criteria of the Vineland Adaptive Behavior Scales (VABS), which was administered to the subjects' parents in interview fashion. VABS scores for the receptive language and expressive language subdomains and the communication and socialization domains were recorded for each subject, and group means were determined for each category.

Between group comparisons were made and results indicated that the ELD group scored significantly lower than the normal group in each area. It was concluded that although the subjects in the ELD group are becoming more proficient in their use of language, they still demonstrate significant differences in their communication and socialization skills as a group.

Within group comparisons were also made from data obtained from the same subjects at two years of age. Results indicate that the performance of the normal group was stable, but the ELD group made a significant gain in their communication skills in the period of one year while their socialization skills remained stable. It was also determined that although the ELD group had scores that were significantly different from the normal group, approximately two-thirds of the ELD group were demonstrating ageappropriate language and socialization skills at three years of age. It was concluded that a majority of the subjects in 
the ELD group can no longer be considered to be delayed according to the criteria set for two year olds. However, it was determined that the subjects most likely to remain classified as delayed were those who at age two were delayed in both expressive and receptive language.

The secondary purpose of this study was to determine whether or not children who spent a significant amount of time in day care demonstrated any differences in their social skills when compared to children who do not spend a significant amount of time in day care.

Data for this portion of the study was obtained by means of a parent questionnaire. Subjects were divided into two groups according to the amount of time spent in day care. Socialization domain age equivalent scores of the VABS were used for comparisons, which were made between groups containing both ELD and normal subjects, and also within diagnostic groups. Results revealed no significant differences. Additional analyses were performed to determine if differences existed in communication skills of the same groups. Again, no significant differences emerged. However, this portion of the study was not well-defined, and therefore the results cannot be used exclusively to conclude that no differences exist in the socialization or communication skills of children who attend day care and those who do not. 


\section{COMMUNICATION AND SOCIALIZATION SKILLS OF THREE YEAR OLDS WITH A HISTORY OF LANGUAGE DELAY}

by

PAMELA SUSAN DAHM

A thesis submitted in partial fulfillment of the requirements for the degree of

MASTER OF SCIENCE

in

SPEECH COMMUNICATION :

SPEECH AND HEARING SCIENCES

Portland State University

1989 
TO THE OFFICE OF GRADUATE STUDIES AND RESEARCH:

The members of the committee approve the thesis of Pamela Susan Dahm presented June 29, 1989.
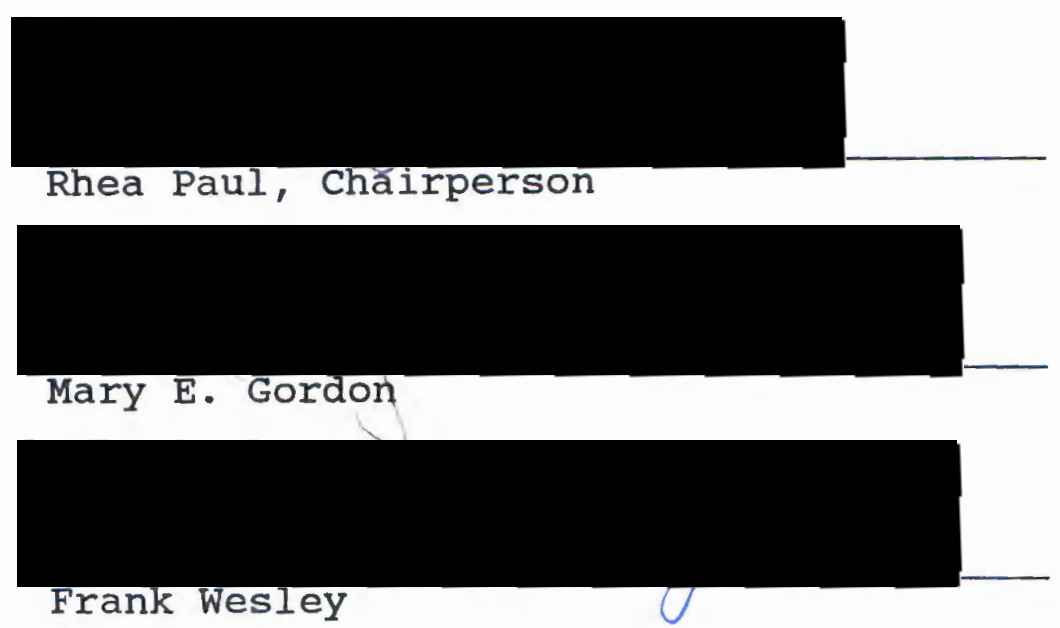

\section{APPROVED:}

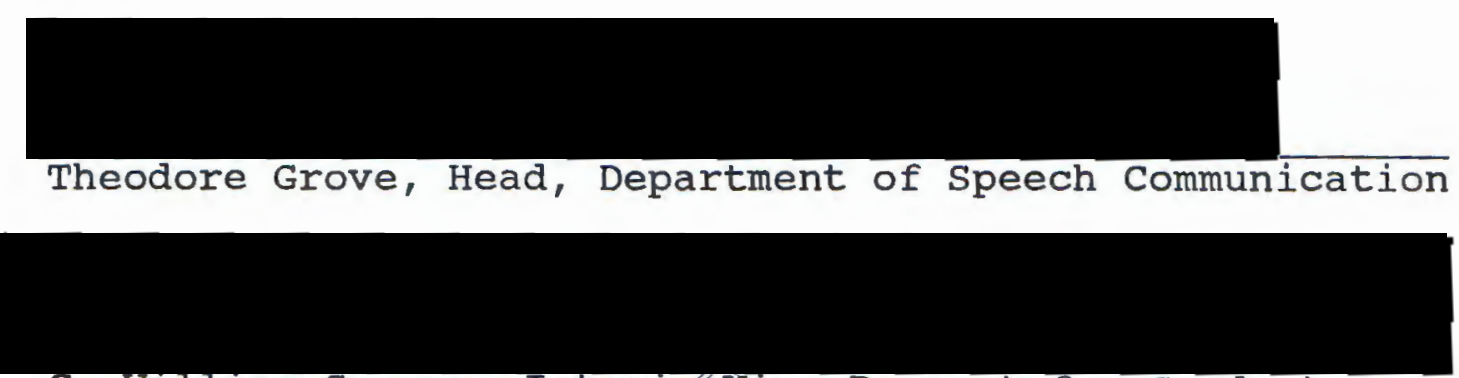

c. william savery, Interim vice provost for Gracuate studies and Research 
TABLE OF CONTENTS

PAGE

LIST OF TABLES

CHAPTER

I INTRODUCTION AND STATEMENT OF PURPOSE • . . . 1

Introduction . . . . . . . . . . . 1

Statement of Purpose . . . . . . . . . 2

Definition of Terms . . . . . . . . . 4

II REVIEW OF THE LITERATURE • • . • • • . . . 7

Expressive Communication . . . . . . 8

Normal Development . . . . . . 8

Delayed Development . . . . . . 9

Receptive Language .. . . . . . . 11

Normal Development ........ 11

Delayed Development . . . . . . 13

Relations between Receptive and

Expressive Communication . . . . . . . 14

Normal Development . . . . . . . . 14

Delayed Development . . . . . . 15

Socialization . . . . . . . . . 17

Relationship between Language

Acquisition and Socialization . . . 19

Socialization Skills and Day Care . . . 21

Vineland Adaptive Behavior Scales . . . 24

Summary . . . . . . . . . 26 
III METHODS AND PROCEDURES . . . . . . . . . 28

subjects . . . . . . . . . . . . . . 28 Subject Recruiting Procedures . . 29 Additional Eligibility Procedures . 30

Instrumentation . . . . . . . . 31

Procedures ............ . 32 Reliability of Data:..... . 33

Data Analysis . . . . . . . . . . 34

IV RESULTS AND DISCUSSION . . . . . . . . 36

Results . . . . . . . . . . . 36

Results of Language Delay and

Social Skills Analysis . . . . . 37

Results of Day Care Analysis . . . 43

Discussion . . . . . . . . . . 45

$\mathrm{V}$ SUMMARY AND IMPLICATIONS ... . . . . . . 49

Summary . . . . . . . . . . . 49

Clinical Implications . . . . . . 51

Research Implications . . . . . . 52

REFERENCES . . . . . . . . . . . . . . . 54

APPENDICES
A LETTER OF INFORMED CONSENT . . . . . . . . . 58
B HUMAN SUBJECT APPROVAL . . . . . . . . 60
C VINELAND ADAPTIVE BEHAVIOR SCALES . . . . . . 62
D DAY CARE QUESTIONNAIRE . . . . . . . . . 67 


\section{LIST OF TABLES}

TABLE

PAGE

I Interrater Reliability . . . . . . . . . •

II Age Equivalent Means and Standard Deviations

in Months for ELD and Normal subjects . .

III Summary of Within Group Comparisons . . . .

IV Standard Score Comparisons . . . . . . .

$\mathrm{V}$ Percentages of subjects Whose communication

and Socialization Standard Scores Are

Less Than 85 at Each Age Level . . . .

VI Percentages of ELD Three Year Olds Whose

Standard Scores are Below 85 . . . . .

VII Day Care Data Compiled from Parent

questionnaire . . . . . . . . . . . .

VIII within and Between Group Comparisons of

Socialization Domain Means and Standard

Deviations for Day Care and Non-Day Care

Subjects . . . . . . . . . . . . . .

IX Between Group Comparisons of Communication

Domain and Subdomain Means and standard

Deviations of Day Care and Non-Day Care Subjects . . . . . . . • . • . • . • 


\section{CHAPTER I}

\section{INTRODUCTION AND STATEMENT OF PURPOSE}

\section{INTRODUCTION}

During the first three years of life, children accomplish many developmental tasks. They go from being persons who react to people and events in the environment to persons who act on the environment. They learn verbal and nonverbal ways to communicate needs and feelings, and they become active participants in interactions with people they know and encounter. They develop a wide range of skills in communication and socialization and use them to learn more about people and the world around them. The skills they use to communicate and the skills they use to be social are somewhat independent from each other, but at the same time are also interdependent. If, for some reason, children have difficulty expressing themselves, they may also be having a difficult time understanding what other people say. This could lead one to assume that they also may be having difficulty in functioning in social ways since communication is often the basis for socialization. If, in fact, socialization skills are retarded along with a language delay, it would be important to emphasize social skills as well as language skills in remediation. 
Another aspect to consider when examining social skills of preschool children is whether or not spending a significant amount of time in day care facilities influences social adaptation. Presently it is very common for many mothers of small children to work outside the home. Therefore, many children in their preschool years are attending day care centers and are exposed to a wide range of social situations that they most likely would not encounter at home. Perhaps by being involved in such a social environment, these children acquire higher level social skills earlier than children who are not exposed to the same conditions. If this is true, it may have implications for the remediation of language delayed children. Since communication and socialization are interrelated, it may be beneficial to language delayed children if part of their remediation includes placing them in a social environment.

\section{STATEMENT OF PURPOSE}

The purpose of this study was to compare receptive language, expressive language, and socialization skills of 36 to 46 month old children who have a history of expressive language delay with normal children of the same age level. Spangle-Looney (1988) found that 18 to 34 month old children who were identified as having an expressive language delay also exhibit delayed receptive language skills and social 
skills according to the criteria of the Vineland Adaptive Behavior Scales (Sparrow, Balla \& Cicchetti, 1984). The same subjects were evaluated approximately one year later and it was determined whether the children who have a history of expressive language delay are still delayed in receptive language and social skills as they have become more proficient in their language use.

The secondary purpose of this study was to determine if there is a significant difference in the social skills demonstrated by children who spend a significant amount of time in day care compared to children who do not (attend day care). If a difference in favor of day care does exist, clinicians involved in language remediation should consider the possibility of adding the strategy of exposing their clients to a concentrated social environment for language enhancement.

The questions that were addressed in this study are:

1. Do children who at age two were considered to have an expressive language delay continue to demonstrate deficits in communication and socialization as measured on the Vineland Adaptive Behavior scales at three years of age?

2. Within diagnostic groups (i.e., normal and expresive language delayed) do children who spend a significant amount of time in day care have more advanced socialization skills than children who do 
not (spend a significant amount of time in day care)?

In order to answer these questions in the affirmative, the null hypothesis of each must be rejected. Therefore, these questions stated as null hypotheses are as follows:

1. Three year old subjects with a history of expressive language delay will show no significant difference in communication and socialization skills relative to normal age mates.

2. Children who spend a significant amount of time in day care will have socialization skills that are not significantly different from children who do not spend a significant amount of time in day care.

\section{DEFINITION OF TERMS}

The following operational definitions were used by Spangle-Looney (1988) and were also used in this study for consistency. Several of them, as noted, are taken directly from the Vineland Adaptive Behavior Scales (Survey Form) (VABS) manual (Sparrow et al., 1984) which is the instrument that was used to assess the subjects' communication and socialization skills.

Expressive Language Delayed (ELD) Subjects: In the initial stages of the study, subjects were considered to have an expressive language delay if they met the following 
criteria: a) if the child was 18-23 months and had a vocabulary of 10 or fewer words; b) if the child was 24-36 months and had a vocabulary of 50 or fewer words or used no two-word combinations (Spangle-Looney, 1988). Subjects initially identified as ELD were also in the ELD group in this study.

Normal Subjects: In the initial stages of the study, subjects were considered to have normally developing language if a) the child was 18-23 months and had a vocabulary of more than 10 words; or b) the child was 24-36 months and had a vocabulary of more than 50 words and used two word combinations (Spangle-Looney, 1988). Subjects initially identified as normal were also in the normal (i.e., control) group in this study.

Expressive Language: The VABS manual defines expressive language as "what the individual says" (Sparrow et a1., 1984, p. 114).

Receptive Language: The VABS manual defines receptive language as "what the individual understands" (Sparrow et al., 1984, p. 114).

Socialization skills: The VABS divides the category of socialization skills into three subcategories: a) "interpersonal relationships - how the individual interacts with others; b) play and leisure time - how the individual plays and uses leisure time; c) and coping skills - how the individual demonstrates responsibility and sensitivity to 
others" (Sparrow et al., 1984, p. 114).

Day care: Day care is defined as an environment outside the home in which the child is in contact with at least five other children.

significant amount of time in day care: This examiner arbitrarily determined 30 hours per week as a significant amount of time for a child to attend day care. subjects that attend day care less than 5 hours per week will not be considered to spend significant amount of time in day care. 


\section{CHAPTER II}

\section{REVIEW OF THE LITERATURE}

"Language is acquired in a social context, through a process made possible by the communication that occurs during social interaction" (Snow, Midkiff-Borunda, Small, \& Proctor, 1984, p. 72). This statement reflects the interrelatedness of socialization and communication during the process of language acquisition. As children interact with people in their environment, they develop and practice a wide variety of social skills. They learn appropriate skills from others' actions, their own actions, and their reactions of others to their actions. The same is true of their communication skills. From very early on, children recognize that communication involves both decoding (or understanding) messages and encoding (formulating and producing) messages. They learn the function, structure, and meaning of language by being active participants in communication.

A review of the normal and delayed development of language (both receptive and expressive) will be discussed, as well as the normal and delayed development of socialization skills. A brief discussion on the influence of day care on social skills will also be included, along 
with a brief overview of the Vineland Adaptive Behavior Scales (VABS) (Sparrow, Balla, \& Cicchetti, 1984) as the VABS was the instrument utilized in this study.

\section{EXPRESSIVE COMMUNICATION}

\section{Normal Development}

Children begin the process of language acquisition in their first months of life. They are responsive to language that is spoken to them by attending to the speaker as well as by being participants in a primitive form of conversation. They soon learn that through their gestures and cries, they can initiate interaction with another human being and therefore acquire social motivation for communicating (Berko-Gleason, 1984).

During their first year of life, children's form of communication goes from reflexive crying and cooing to complex forms of babbling (Berko-Gleason, 1984; Bloom \& Lahey, 1978). When the children are approximately one year of age, their first recognizable words emerge (Bloom \& Lahey, 1978; Chapman, 1982). First words that are spoken usually are tied to isolated objects or events, and are used to label people or objects or are part of a social routine (Bloom, 1974). Often children will use one word to describe several items that share a common feature. This overuse of a word is referred to as overextension, and it 
continues to occur as the children increase their vocabularies.

By the time children are 2 years of age, they produce about 50 words. Up until this time, they may use single words to convey the messages of whole sentences (BerkoGleason, 1984). They may now begin to combine two words, usually nouns, verbs, and adjectives (Berko-Gleason, 1984). Bloom (1970) suggested that children express several different semantic relations with one two-word combination. For example, "Mommy sock" could be used to ask the child's mother for a sock or to state that the sock belongs to Mommy .

By the time children are 3 years of age, their utterances are beginning to sound more adult-like. Their mean length of utterance (MLU) is approximately 4.0 and the syntactic complexity of their utterances increases (Chapman, 1982). Their sentences contain both noun phrases and verb phrases, and they can talk about past events (Miller, 1981). Children become fairly proficient in their use of language and continue to refine it throughout the preschool period.

\section{Delayed Development}

Bloom and Lahey (1978) describe language acquisition in terms of three interacting components: content, form, and use. Children who develop language normally can integrate the three parts effectively. Bloom and Lahey define disordered language as "any disruption within a component or 
in the interaction among the components" (p. 291). Therefore, an expressive delay could result from a disruption in the integration of either form or use. This could happen at any point along the language learning continuum and to any degree of severity. Examples listed by Bloom and Lahey (1978) include being able to communicate by using gestures but not words and word finding difficulties. Thal and Bates (1988) examined the language and gestures in late talking preschoolers. They found that their group of late talking preschoolers used more gestures than the normal group, and suggested their use of gestures may be in some way related to word finding problems. They determined that all of the subjects had at least partial development of a lexical base, and the patterns of delay that they observed would probably disappear over time. However, they noted that the prognosis for children who have delays in comprehension as well as production was not as good.

In their study of semantic relations, Leonard, Bolders, and Miller (1976) matched language delayed children and children with normally developing language both in terms of chronological age and mean length of utterance (MLU). They found that language delayed children scored significantly lower than the normal children of the same age on word order tasks in production. However, they found that the groups matched for MLU had almost identical scores, suggesting that 
language delayed children follow a normal developmental pattern.

\section{RECEPTIVE LANGUAGE}

\section{Normal Development}

As it has been previously defined, receptive language refers to what children understand. Since no one can accurately measure what small children comprehend, very little research has been done in the area of early receptive language. Menyuk (1974) describes receptive language as "perceiving the structural properties of language" and "understanding the communicative functions of these properties" (p. 213).

Eimas (1974) found that by one month of age, infants can discriminate between the phonemes $/ \mathrm{p} /$ and $/ \mathrm{b} /$, and by 2 months, can perceive differences in place of articulation in an adult-like fashion. Also, by 2 months, they can differentiate between rising and falling intonation (Menyuk, 1974). Between 2 to 4 months, children respond differently to male and female voices, angry and friendly voices, and familiar and unfamiliar voices (Kaplan \& Kaplan, 1970, cited in Menyuk, 1974). By 5 to 8 months, children appear to be able to differentiate between statements and questions, and show preference for the human voice over nonspeech sounds (Menyuk, 1974).

It is unclear when children understand individual 
words. Bloom (1974) suggested that the first words children understand are ones that are tied to objects or events in the children's immediate environment. Often they are limited to one specific object or event, until children begin to realize that a word can be a referent for an entire category at about age two (Berko-Gleason, 1984; Bloom, 1974). Chapman (1982) stated that by the time the children are 16 months, they can understand words without contextual clues. It is fairly universally agreed upon that between the ages of 1 and 2 , children understand more than they can produce (Bloom, 1974; Chapman, 1982; Ingram, 1974). Chapman (1978) suggested that children use comprehension strategies to derive meaning from utterances spoken to them instead of actually understanding what has been said. The children's strategies change with their progression through Piaget's stages of cognitive development (Piaget, 1969; cited in Chapman, 1978). When children are 8-12 months and they are in Piaget's Sensorimotor stage IV, they appear to understand by looking at what the speaker looks at, acting on an object that the caregiver notices, or by imitating another's actions.

When children are 12-18 months and they are in Piaget's Sensorimotor stage $V$, they are at the one word production level, and also understand single words. They may appear to understand complete sentences by attending to the object mentioned, giving evidence of notice, or by doing 
what is usually done in the situation (Chapman, 1978).

By the time they are 18-24 months and are in Piaget's Sensorimotor stage VI, they have understanding of words, but rely on contextual cues for their meanings. The strategies they use now include locating objects mentioned or giving evidence of notice, doing what is usually done by showing conventional use or putting objects in containers, and acting on objects in the way mentioned with the child as the agent (or one performing the action) or by choosing the handier object as the instrument (Chapman, 1978).

During the preschool years (age 2-4 years), children enter Piaget's Early Preoperations stage and continue to interpret meaning from context, but also use past experience. When asked to perform a task, they do what is usually done using a probable location strategy or probable event strategy. When asked a question, they will supply missing information even without understanding the intent of the question. It is not until children reach 4 years of age, during Piaget's Late Preoperational stage or Concrete operation stage, that they understand in terms of word order (Chapman, 1978).

\section{Delayed Development}

Paul, Fischer, and Cohen (1988) examined the comprehension strategies of children with autism and expressive language delays, with mean receptive language ages of 32.7 and 35.4 months, respectively, to determine 
whether their strategies differ from children with normally developing language. They found that the autistic children and the expressive language delayed children shared similar patterns of strategy use, but both groups differed from the normal pattern described in the preceding section. Both the autistic and language delayed children demonstrated use of word order strategy over probable event strategy. This is evidence that expressive language delayed children do not use the same pattern of comprehension strategies as normal children do. The authors suggested that perhaps because language delayed children remain in the two and three word combination stages, they have more experience with word order and therefore develop that strategy at an earlier age.

RELATIONS BETWEEN RECEPTIVE
AND EXPRESSIVE COMMUNICATION

Normal Development

The relationship between receptive language (comprehension) and expressive language (production) is a major source of controversy when discussing the process of language acquisition. As has been previously stated, comprehension most likely precedes production during the first year and up until the time the child begins to combine words. But after that time, researchers disagree as to which has a more predominant role during the preschool years. 
Bloom (1974) is of the opinion that comprehension and production do not develop separately and that "the two represent mutually dependent but different underlying processes, with a resulting shift of influence between them during the course of language development" (p. 286). Menyuk (1974) suggests that comprehension and production are closely related and that one cannot be discussed without the other. She also believes that there are periods of reorganization during the course of language development for both comprehension and production in which the influence of each changes. Ingram (1974), on the other hand, is of the opinion that comprehension precedes production at every step along the way during language development.

Several studies have been done on the comprehension and production of word order. Chapman and Miller (1975) examined preschool children's ability to act out semantically reversible sentences and produce sentences that were of the subject-object form. They found that the subjects produced more sentences accurately than they understood them. Fraser, Bellugi, and Brown (1963) completed a similar study in which they tested imitation, comprehension, and production of the same syntactical form. In contrast to Chapman and Miller, they found that comprehension preceded production in this type of task.

\section{Delayed Development}

Since it is difficult to describe the relationship 
between comprehension and production in normally developing language, it is nearly impossible to describe it in delayed language development. Children who are delayed in their language development are a heterogenous group - no two children have identical problems. Some children are late in saying their first words and continue to be delayed in obtaining other language acquisition milestones. Some children who begin using single words within the normal time frame continue to use them exclusively long after they would have been expected to combine words (Reed, 1986). Therefore, when discussing the possible relationships of comprehension and production in delayed language development, one must take into account the diversity and realize that no generalizations can be made.

Menyuk (1974) proposed that perhaps language delayed children are delayed in their ability to reorganize their comprehension and production skills at the various stages of language development. Leonard et al. (1976) matched language delayed and normal subjects in terms of MLU and examined their production skills in semantic relations. They found that the delayed subjects demonstrate almost identical patterns of production as the younger normal subjects. This suggests that language delayed children follow the same developmental pattern as normal children do, but that they obtain their milestones more slowly.

Paul and spangle-Looney (1987) compared expressive and 
receptive language skills of toddlers who were considered to be delayed in their expressive language. They found that $30 \%$ of the delayed group scored significantly lower than the normal subjects in both areas of receptive and expressive language. This suggests that comprehension delays often accompany delays in production.

In summary, the relationship between comprehension and production is not well understood. It appears that at various times in children's language development period, there is a shift of influence between them. Just as the relationship between comprehension and production cannot be determined in normal language development, it cannot be done for delayed language development. Research suggests, however, that delays in comprehension often accompany delays in production.

\section{SOCIALIZATION}

Socialization is defined by Arwood (1983) as the ability to share meaning with another person. She stated that "socialization is a primary reason for the speaker organizing incoming stimuli into meaningful units that could be used to affect the attitudes, beliefs and/or behaviors of another person" (Arwood, 1983, p. 50). She also believes that humans have an innate nature to interact with others. Prutting (1982) describes socialization as being closely related to both cognitive and language development. 
Therefore, socialization cannot be described independently of language.

From the time infants are born, they are in a social environment. During their first months of life, they make socially appropriate responses to their caregivers' speech by paying attention to them and by making eye contact with them. In a primitive way, they even take their turn in conversation by sharing joint attention. They soon learn that through their gestures and cries, they can initiate interaction with another human being and therefore acquire a social motivation for communicating. When their message is not understood, they modify their strategy in an attempt to communicate more clearly (Berko-Gleason, 1984). These gestures, eye contact, and vocalizations have been labeled communicative intents by Scoville (1983, cited in BerkoGleason, 1984). As Bloom and Lahey (1978) point out, infants are sensitive to the role context plays in socialization.

As children progress through their first year, they become increasingly more social. They engage in routine play such as pat-a-cake and respond to play appropriately with laughs and gurgles. Their social motivation is evident in the first words they learn. Nelson (1973) states that of the first 50 words a child learns, half of them are associated with social routines (cited in Bloom and Lahey, 1978) . 
By the time children are 2 to 3 years of age, they are capable of interacting with other children for short periods of time. They form what Roth and clark (1987) term dyadic peer relations. However at this point, most of the children's play is either solitary or parallel, which means that two children may be playing side by side, but without interaction.

Relationship between Lanquage Acquisition and Socialization

The Social Interaction Theory of language acquisition states that the "structure of human language may have arisen from the social-communicative functions language plays in human relations" (Bates and MacWhinney, 1982, cited in Berko-Gleason, 1984). Vygotsky (1962) states "language is first only a tool for social interaction and later becomes a personal tool" (cited in Berko-Gleason, 1984, p. 193). The view that has been presented in this paper is that language skills and socialization skills are very closely related. Children do not learn language without learning associated social skills.

Prutting (1982) stated that while children are learning rules for syntax and semantics, they are at the same time learning the context in which they can use those rules. She suggests that a person learns language content, form, and use according to what is demanded by his/her social environment. In fact, she believes that "the social interaction framework is the foundation for the [language] 
acquisition process" (p. 129), and that a person's social competence is based on his or her language use. It is no wonder, then, that children with delayed language skills are often considered to be socially incompetent.

Since language delayed children have a more difficult time interacting with people in their environment, they are somewhat at risk for having accompanying behavior problems. Mattison, Cantwell, and Baker (1980) examined this issue and found that children with language disorders do in fact tend to have some type of behavior disorder. Most often, the behavior disorders exhibited were attentional-motor and relationship problems. It is evident that either could be the result of a comprehension and/or production deficit.

Paul and Spangle-Looney (1987) examined the socialization skills of expressive language delayed children and normal children. They found that $90 \%$ of the expressive delayed subjects demonstrated social skills that were at least six months behind what was expected for their chronological age.

In summary, communication and socialization skills are closely related. They appear to develop simultaneously and may have a causal relationship. Children who have a solid language base in both comprehension and production are more likely to function socially than children who do not. 


\section{SOCIALIZATION SKILLS AND DAYCARE}

Within current society, more and more mothers of small children are working outside the home; therefore, an increasing number of children are attending day care. There has been some debate as to whether spending a significant amount of time in day care has an affect on developing social skills. According to Klass (1986), the family is traditionally responsible for establishing and molding young children's patterns of relating with others and societal values and attitudes, all of which are directly related to socialization. This leads one to speculate that by spending a significant amount of time in day care, which is a social setting, children will develop attitudes and patterns of relating that are more complex than the traditional ones learned at home.

Klass (1986) lists several social experiences that are typical within the day care setting, including conversation with people of varying status, helping peers and teachers, sharing, combining efforts with other children to complete tasks, and recognizing the feelings of others in an empathetic way. While engaging in these activities, the children usually are not the focus of the interaction, but instead share the focus with another person. The scope of people with whom the children interact is much larger in the day care setting, and therefore the children learn to adjust their interactions accordingly. 
Even though Klass (1986) recognizes that these social activities exist, she argues that most day care settings stress individualism instead of social interaction. She points out that although the children are within a social context, they still engage in individualistic and selfcentered behavior. These behaviors include solitary play, seeking teacher praise for self accomplishment and maintaining individual rights to possessions and space. Therefore, she feels that children who attend day care do not necessarily develop more advanced social skills than children who spend more time at home.

Moore (1964) reports that children who experience day care before the age of five tend to show more negative social behaviors than children with no day care experience. These children tend to be less conforming, more selfassertive, and less impressed by punishment. All of these characteristics could be considered to be slightly negative.

In Belsky and Steinberg's (1978) critical review of literature on day care, three common themes emerged. Studies they reviewed supported the claims that day care experiences had neither advantageous or detrimental effects on children's intellectual development, did not interrupt the emotional bond between mother and child, and did increase the amount of both positive and negative interactions with peers. The main point that was stressed by Belsky and Steinberg (1978) was that each day care 
experience is highly individual, and effects from various programs would be highly variable, depending on the focus of the program and the training of the staff.

Rutter (1982) states that the amount of time a child has attended day care will effect his or her social abilities. He claims that children who are "reared" in the day care setting from babyhood on make different adjustments in their behaviors than those who enter day care after firm bonds have been established with other care givers in less social environments. These differences, however, are not necessarily considered to be either positive or negative. Schwartz, Strickland, and Krolick (1974) support this claim by stating that young children who have spent a great deal of time in the day care environment have a different style of interacting socially than children experiencing day care at a later age. Rutter (1982) concludes that these "style" differences appear to be related to individual maturation and amount of peer group experience of each child, rather than home care or day care.

In summary, there are conflicting views on whether or not day care experience has an effect on a child's socialization skills. Although proponents for each side of the issue have reported both positive and negative effects, it appears that no major socialization differences have been found in children who attend day care and those who do not. 
VINELAND ADAPTIVE BEHAVIOR SCALES

The Vineland Adaptive Behavior Scales (VABS) was developed as a result of legislation dictating the need for wider application of adaptive behavior assessment. Adaptive behavior is defined as "the performance of daily activities required for personal and social sufficiency" (Sparrow et al., 1984, p. 6). The VABS divides adaptive behavior into four domains: communication, daily living skills, socialization and motor skills. Each domain contains behavioral descriptions arranged in developmental order and encompasses behaviors from birth to adulthood.

The VABS was developed over a period of six years. The assessment items were selected through a series of pilot tests and a national tryout. The subjects in the norming sample were chosen to match the U.S. Census figures for the population of 1980 for sex, geographical location, race and parental education level (Sparrow et al., 1984).

The VABS is an extremely valid and reliable assessment tool. Split-half reliability coefficients for the Adaptive Behavior Composite (i.e., the total score) ranged from .89 .90 for the survey form. Test-retest reliability coefficients ranged from .80 's - .90's which is also very good, as were measures of construct, content, and criterion related validity (Sparrow et al., 1984).

The VABS is presented to the parent or the primary caregiver of the subject in an interview style. The 
interviewer asks open-ended questions that focus on what the subject does as opposed to does not do. Questions are asked in order from general to specific and are scored in terms of how often the subject performs each behavior.

In the initial stages of this present study, SpangleLooney (1988) compared VABS age equivalent scores of the four domains of 2 year old subjects that were either normal or identified as having a language delay. Due to the fact that no significant differences were noted between the two groups in either the daily living or motor skills domain, the main focus of this study will be the communication and socialization domains. The communication domain is divided into three categories: receptive, expressive, and written. Categories within the socialization domain include interpersonal relationships, play and leisure time, and coping skills.

In summary, the instrument that was utilized in this study is the Vineland Adaptive Behavior scales (Survey Form) (Sparrow et al., 1984). Although it assess a wide range of behaviors, it was used only to assess receptive language, expressive language, interpersonal relationships, play and leisure time, and coping skills in this study. since the VABS has very good validity and reliability measures, it was expected that the results will be an accurate description of each subject's communication and socialization skills. 
SUMMARY

The sequence of normal and delayed language development during the preschool years was discussed. It appears that children with expressive language delays follow the same pattern of development as normal children but at a slower pace (Leonard, Bolders, and Miller, 1976). Not much is known about receptive language development due to the fact that it is difficult to measure. Therefore, it is also difficult to determine if receptive language development is different in language delayed children. The relationship between comprehension and production is very complex and has been the subject of debate. The two appear to be different skills, but yet are interrelated, with alternating influence over the course of language development (Bloom, 1974). Socialization skills appear to be closely tied to language development. Children learn most of their language in social contexts and therefore learn to use their language as a tool for interaction (Prutting, 1982). Children who are proficient in their language use tend to have better social skills than children who do not use their language as well. In fact, a child's social competence is often determined by how good a communicator he is (Roth \& Clark, 1987).

The Vineland Adaptive Behavior Scales (Sparrow et al., 1984) is a valid and reliable instrument and was used to assess the subject's communication and socialization skills. 
It is a developmental scale that is presented in interview fashion to the parent or caregiver, and assesses a wide range of behaviors. 
CHAPTER III

METHODS AND PROCEDURES

SUBJECTS

The subjects in this study are involved in an ongoing longitudinal study under the direction of Dr. Rhea Paul at Portland State University. When the study began, the 54 subjects were between the ages of 24 months and 34 months. This study was done approximately one year after the initial assessment, and the subjects ranged in age from 36 months to 48 months. Half of them were considered to have a history of expressive language delayed (ELD) and half were considered to be normal according to the criteria set during the initial stages of the study.

The criteria for establishing the language status of the subjects are as follows. The subjects were considered to have an expressive language delay if they met the following criteria: a) if the child was 18-23 months and had a vocabulary of 10 or fewer words; b) if the child was 24-36 months and had a vocabulary of 50 or fewer words or used no two word combinations. The size of the subject's vocabulary was determined by parent report.

The subjects were considered to be normal if, by parent report, a) he or she was 18-23 months and had a vocabulary 
of more than 10 words; or b) he or she was 24-36 months and had a vocabulary of more than 50 words and used two word combinations.

\section{Subject Recruiting Procedures}

The subjects were recruited following two procedures. The first procedure involved the distribution of questionnaires from local pediatric clinics. Mothers bringing their children in for 15 month and 24 month well visits were asked to complete the questionnaires if they were interested in participating in the study. Information obtained on the questionnaire included the parents' occupations, the child's birthdate, the number of different words the child used, and whether or not the child used two word combinations. Parents were also asked if they would be willing to participate at a later time. The information provided on this form served as the basis for determining the child's expressive language status according to the criteria listed previously.

The second recruitment procedure involved the use of local media sources. An article was run in the local newspaper that described the study and stated the need for volunteers, and a local radio station broadcasted a request for subjects during a newscast. Parents who responded were contacted and given the same questionnaire that was distributed at the pediatric clinics. The children's expressive language status was again determined from the 
information provided by the parent and according to the criteria listed previously.

Two groups of subjects were formed from a pool based on the questionnaire information: a control group and an ELD group. The groups were matched for chronological age and were matched as closely as possible for race, sex, and socioeconomic status (SES). The ELD group consisted of 22 males and 7 females, with a mean age of 26.0 months and a standard deviation of 3.93 months. The control group consisted of 19 males and 10 females, with a mean age of 25.4 months and a standard deviation of 4.56 months. of the ELD group, 28 subjects were Caucasian (97\%), and of the control group, 26 were Caucasian (90\%). Mean SES was determined according to the procedures of the two factor index which combines occupation and parental education (Meyers \& Bean, 1968). Weighted scores were derived for each subject as well as an overall score of 1 to 5 ( 1 being the highest SES level and 5 the lowest). For the ELD group, mean SES was 2.9 with a standard deviation of 1.05 , and for the control group, the mean SES was 2.6 with a standard deviation of 1.37 (Spangle-Looney, 1988).

\section{Additional Eligibility Procedures}

Parental permission forms were completed during the initial assessment at Portland State University as well as a vocabulary checklist. The vocabulary checklist was used to determine whether the child's vocabulary size and use of two 
word combinations were within the limitations set by the definition of expressive delayed subjects.

None of the subjects had known physical handicaps, were mentally retarded, or had other disabilities such as autism that might effect normal language development. All subjects were found to be within the normal range for their cognitive development on the Bayley scales of Infant Development (Bayley, 1969) or the stanford-Binet Intelligence Scale (Terman \& Merrill, 1960), depending on age. These tests were administered by a trained psychologist. Children with standard scores over 85 were included in the study.

The subjects also were required to pass a hearing screening which was done by the sound field procedure. All passed at $25 \mathrm{~dB} \mathrm{HL}$ except for one subject who was uncooperative and one who passed at $40 \mathrm{~dB} \mathrm{Hl}$.

\section{INSTRUMENTATION}

The instrument that was used to evaluate receptive and expressive language skills and socialization skills in the initial study was the Vineland Adaptive Behaviors Scales, (VABS), (Sparrow, Balla, \& Cicchetti, 1984). The VABS is a developmental scale that is divided into four domains: communication skills, daily living skills, socialization skills, and motor skills. Each domain is further divided into subdomains to aid in pinpointing the subject's 
strengths and weaknesses. The items are presented to the primary caregiver of the child in interview fashion. The domains and subdomains are scored in terms of raw scores, standard scores, national percentile rank, stanine, adaptive level, and age equivalents.

\section{PROCEDURES}

The VABS was administered to the primary caregiver of each subject in a face-to-face interview or in a telephone conversation. Rapport was established with the caregiver and a description of the assessment was given. Assessment topics began with a general question and were followed by more specific questions and prompts. The scores for each domain and subdomain was recorded on the test booklet and on data charts.

Each caregiver was asked to fill out a short questionnaire regarding the subject's daycare attendance. Questions included whether or not the subject attends daycare, the average amount of time spent in a daycare environment, type of daycare, and the number of children in the daycare setting. Two groups of subjects within each diagnostic group were formed on the basis of the questionnaires. Subjects who spend less than 5 hours per week in daycare comprised the control group within each diagnostic group. Children who attend daycare more than 30 hours per week were considered to spend a significant amount 
of time there and comprised the experimental group within each diagnostic group. Children spending between 5 and 29 hours per week in day care were excluded.

\section{Reliability of Data}

Interviews were done by several different researchers, all of whom were involved directly with the longitudinal study. None of the researchers were aware of the group classification of the child during the interview process. Approximately $15 \%$ of the interviews were randomly selected to be scored by an additional researcher, who was present at the time of the interview. Scores were arrived at independently by the two researchers, and interrater reliability was determined by percent agreement for each item scored in the communication and socialization domains and the receptive and expressive subdomains (Table I). Reliabilities ranged from 92-100\%.

\section{TABLE I}

\section{INTERRATER RELIABILITY}

Subj. Rec. Expr. Comm. Social Mean

$\begin{array}{lrrrrr}\# 114 & 100 \% & 92 \% & 94 \% & 100 \% & 97 \% \\ \# 119 & 100 \% & 100 \% & 100 \% & 100 \% & 100 \% \\ \# 142 & 100 \% & 100 \% & 100 \% & 100 \% & 100 \% \\ \# 128 & 100 \% & 100 \% & 100 \% & 100 \% & 100 \% \\ \# 69 & 100 \% & 98 \% & 98 \% & 100 \% & 99 \% \\ \# 57 & 92 \% & 100 \% & 98 \% & 98 \% & 97 \% \\ \# 91 & 100 \% & 100 \% & 100 \% & 100 \% & 100 \% \\ \# 26 & 100 \% & 100 \% & 100 \% & 100 \% & 100 \%\end{array}$


DATA ANALYSIS

The scores that were used for analysis are the communication skills and socialization domain age equivalents and standard scores and subdomain age equivalents and adaptive levels. Standard scores are not available in the VABS manual for subdomains. However, adaptive levels indicate the number of standard deviations from the mean at which a child's score falls. An additional comparison of the subjects' scores in this study and the scores in the initial study was done in a cross-sectional fashion. The scores were analyzed in terms of:

1. Receptive language scores of ELD group compared to receptive language scores of the normal group;

2. Expressive language scores of ELD group compared to expressive language scores of the normal group;

3. Receptive language scores of the ELD group compared to expressive language scores of the ELD group;

4. Receptive language scores of the normal group compared to the expressive language scores of the normal group;

5. Socialization scores of the ELD group compared to the socialization skills of the normal group;

6. Socialization scores of subjects (either ELD or normal) that spend a significant amount of time in day care compared to socialization scores of subjects who do not.

A one-tailed t-test for unmatched groups was used to compare the age equivalent means of the various subdomains and domains within diagnostic groups.

A two-tailed t-test for unmatched groups was used to 
determine if there is a significant difference in the social skills of children who spend a significant amount of time in daycare and those who do not attend daycare within each diagnostic group. 
CHAPTER IV

RESULTS AND DISCUSSION

RESULTS

The purpose of this study was to compare receptive language, expressive language, and socialization skills of 36 to 46 month old children who have a history of expressive language delay with normal children of the same age level. The mothers of each of the subjects were interviewed according to the procedures of the Vineland Adaptive Behavior Scales (VABS), and scores were derived from the mothers' responses. The scores were analyzed using a procedure similar to the one used by Spangle-Looney (1988) to determine if the expressively delayed subjects continued to demonstrate delays in expressive language, receptive language, and social skills.

The secondary purpose of this study was to determine whether or not children who spent a significant amount of time in day care demonstrated any differences in their social skills when compared to children who do not spend a significant amount of time in day care. Data for this portion of the study was collected by means of a questionnaire that was mailed to each subject.

Two questions were posed. First, do children who at 
age two were considered to have an expressive language delay continue to demonstrate differences from normals in the communication and socialization domains of the vineland Adaptive Behavior Scales at three years of age? And second, within diagnostic groups, do children who spend a significant amount of time in day care have more advanced social skills than children who do not spend a significant amount of time in day care?

To answer both of these questions, age equivalent scores of the VABS expressive and receptive communication subdomains and communication and socialization domains, and standard scores of the communication and socialization domain were compared for both groups of subjects. Scores from the daily living skills domain and the motor skills domain were not analyzed due to the fact that spangle-Looney (1988) found that they did not differ significantly in the normal and ELD groups.

Each group consisted of 27 subjects and a one-tailed $t-$ test for unmatched groups determined that no significant difference existed between groups for the mean chronological age at the time of the test administration.

Results of Lanquage Delay and Social Skills Analysis

To answer the question of whether or not the subjects with a history of language delay still demonstrated differences in communication and socialization domains at age three, a one-tailed t-test for unmatched groups was used 
to analyze various pairs of means. Results revealed significant differences between ELD and Normal subjects in expressive language, receptive language, the communication domain, and the socialization domain, with the ELD group scoring lower in each category. Age equivalent means in months for each subdomain and domain analyzed, standard deviations and the results of the comparisons between the two groups are presented in Table II.

\section{TABLE II}

AGE EQUIVALENT MEANS AND STANDARD DEVIATIONS IN MONTHS FOR ELD AND NORMAL SUBJECTS

Mean $\stackrel{\text { ELD }}{\stackrel{\text { Normal }}{\text { S.D. }} \text { Mean }} \quad \underline{t} \quad \underline{p}$

Chronological Age $38.37(2.39) \quad 38.70(2.95) \quad .45$ NS Receptive Comm. $\quad 36.78$ (9.41) 43.56 (6.59) 3.07 .005 * Expressive Comm. 31.15 (6.02) 44.74 (8.08) 7.01 .0005* Comm. Domain $\quad 32.26(6.29) 44.11(5.18) \quad 7.55 .0005$ * Social. Domain $29.44(5.36) \quad 37.26(7.21) \quad 4.52 .0005 *$ * significant

Within group comparisons of expressive and receptive scores were also made. There was a significant difference between the expressive scores and receptive scores of ELD subjects, while there was no significant difference found in expressive and receptive scores of normal subjects (Table III) • 
TABLE III

\section{SUMMARY OF WITHIN GROUP COMPARISONS}

\begin{tabular}{|c|c|c|c|}
\hline Pair of Means Compared & $\frac{\text { Difference }}{\text { of means }}$ & $\underline{t}$ & $p<$ \\
\hline Recep. vs. Expr. of ELD & 5.63 & 2.62 & $.01 *$ \\
\hline $\begin{array}{l}\text { Recep. vs. Expr. of Norm. } \\
\text { *significant }\end{array}$ & -1.18 & .58 & NS \\
\hline
\end{tabular}

Since the results of the analyses were consistent with spangle-Looney's (1988) findings, additional analyses were performed to determine if there were any significant changes in group performance over the one year period. Standard scores of the communication and socialization domains from both the two year data and the three year data were used for comparison instead of age equivalent scores, which are not consistent over time. Group means for communication skills and social skills of each group at two years were compared with the group means at three years. Results revealed that the communication and socialization standard scores of the ELD subjects were low for age level at two years, and remained low at three years, whereas the normal subjects' scores were at age level during both testing periods. However, the mean communication domain standard score for the two year ELD subjects was significantly lower than the mean for three year ELD subjects, while the standard scores 
for socialization remained stable from age two to three in this group. The data and results of these analyses are presented in Table IV.

TABLE IV

STANDARD SCORE COMPARISONS

Group Domain $\underline{2}$ Yr.SS $\quad \underline{3 Y r}$.SS $\quad \underline{t} \underline{p<}$ MEAN (SD) MEAN

(SD)

Norm. Comm. $108.30 \quad 12.11 \quad 107.7 \quad 7.84 \quad .22 \quad$ NS

Norm. Soc. $\quad \begin{array}{lllllll}96.63 & 17.01 & 97.40 & 10.47 & .20 & \text { NS }\end{array}$

ELD Comm. $78.70 \quad 6.06 \quad 91.19 \quad 11.42 \quad 5.02 \quad .001 *$

$\begin{array}{lllllll}\text { ELD SOC. } & 84.00 & 6.86 & 87.26 & 9.12 & 1.49 & \text { NS }\end{array}$

*significant

From the national standardization sample, the authors of the VABS were able to establish criteria to categorize subjects' scores in terms of performance level for their age groups. The categories or "adaptive levels" are ranked from low to high, and are defined by a range of standard scores. According to these criteria, subjects whose standard scores are within the range of 70 to 84 are categorized as moderately low for their age group, and those with standard scores below 69 are categorized as low. Table $\mathrm{V}$ represents the percentages of subjects falling in the low and moderateIy low categories for their age groups as determined by VABS criteria for the communication and socialization domains. 


\section{TABLE V}

PERCENTAGES OF SUBJECTS WHOSE COMMUNICATION AND SOCIALIZATION STANDARD SCORES ARE LESS THAN 85 AT EACH AGE LEVEL

Communication

2 yr 3 yr

Normal

Delayed
$0 \%$

$88 \%$
$0 \%$

$33 \%$ $\frac{\text { Socialization }}{2 \text { yr } 3 \text { yr }}$

$0 \% \quad 0 \%$

Spangle-Looney (1988) also found that within the ELD group, two subgroups existed. Seventy percent of the two year old ELD subjects had language delays that were expressive only, and $30 \%$ had delays that were both expressive and receptive, using a criterion of age equivalent scores of six months or more below chronological age. Further analyses were done to determine the percentages of three year subjects in each subgroup of the ELD sample whose standard scores in the communication and socialization domains remained classified as either moderately low or low according to VABS criteria. In examining the data, it was determined that five of the seven subjects identified at two years as having both expressive and receptive delays still had standard scores below 85 in each domain, while six of the eighteen subjects in the expressive delay only subgroup had standard scores 
below 85. The percentages of three year old ELD subjects that remained within each subgroup are presented in Table VI.

\section{TABLE VI}

PERCENTAGES OF ELD THREE YEAR OLDS WHOSE STANDARD SCORES ARE BELOW 85

\begin{tabular}{|c|c|c|c|}
\hline \multirow{3}{*}{$\begin{array}{l}2 \text { yr Subgroup } \\
\text { Expressive }+ \\
\text { Receptive }\end{array}$} & \multirow[b]{2}{*}{$\underline{\mathrm{n}}$} & \multicolumn{2}{|c|}{$\frac{\% \text { of ELD Subjects Scoring Low }}{\text { or Moderately Low }}$} \\
\hline & & Communication & Socialization \\
\hline & 7 & $71 \%$ & $71 \%$ \\
\hline $\begin{array}{l}\text { Expressive } \\
\text { Only }\end{array}$ & 18 & $22 \%$ & $28 \%$ \\
\hline
\end{tabular}

In summary, the results of the analyses performed on the three year data indicate that the group of children who have a history of expressive language delay still scores significantly lower on the VABS in the areas of expressive language, receptive language and social skills. Also, receptive skills of the ELD group are significantly lower than their expressive skills. In comparing each group's performance over time, it appears that the normal subjects as a group remained normal in both communication and socialization domains, and the delayed subjects as a group remained delayed in both domains. The ELD group's scores in the communication domain, however, were significantly higher at three years than at two years, while their socialization 
performance was essentially unchanged. It was also determined that the percentages of subjects that remained in the subgroups identified by Spangle-Looney (1988) is lower at three years than at two, with a large proportion of the expressive only subgroup having acquired both communication and social skills that are adequate for their age group.

\section{Results of Day Care Analysis}

Separate subject groups were formed to answer the question regarding day care and social skills. The group containing subjects who spent a significant amount of time in day care (DC group) consisted of 8 subjects, 3 of whom were ELD and 4 normal. The group containing subjects who do not spend a significant amount of time in day care (NDC group) consisted of 14 subjects, 6 of whom were ELD and 8 normal. See Table VII for data regarding average number of hours spent in day care per week, and the average number of children in addition to the subject per environment.

\section{TABLE VII}

DAY CARE DATA COMPILED FROM PARENT QUESTIONNAIRE

\begin{tabular}{|c|c|c|c|}
\hline Group & \# of subjects & $\frac{\text { mean \# hours }}{(\mathrm{SD})}$ & $\frac{\# \text { children }}{\text { (SD) }}$ \\
\hline DC & 8 & $42.5 \quad(3.78)$ & $16.75(6.58)$ \\
\hline NDC & 14 & 0 & 0 \\
\hline
\end{tabular}


A two-tailed t-test for unmatched groups was used to determine if there was a difference in social skills of children who spend a significant amount of time in day care and of children who do not. Comparisons were made within diagnostic groups and also between groups containing both ELD and normal subjects. Results revealed no significant difference in either case (See Table VIII).

TABLE VIII

WITHIN AND BETWEEN GROUP COMPARISONS OF SOCIALIZATION DOMAIN MEANS AND STANDARD DEVIATIONS FOR DAY CARE AND NON-DAY CARE SUBJECTS

\begin{tabular}{|c|c|c|c|c|c|c|}
\hline \multirow[b]{2}{*}{ Group } & \multicolumn{2}{|c|}{ Day Care } & \multicolumn{2}{|c|}{ Non-Day Care } & $\underline{t}$ & $\mathrm{p}<$ \\
\hline & $\begin{array}{l}\text { Mean } \\
\text { (in mo.) }\end{array}$ & (SD) & $\begin{array}{l}\text { Mean } \\
\text { (in mo. }\end{array}$ & $(\mathrm{SD})$ & & \\
\hline ELD & 27.00 & 4.36 & 29.67 & 3.61 & .72 & s \\
\hline Normal & 36.80 & 2.77 & 37.50 & 7.56 & .19 & 15 \\
\hline ELD + Norm & 33.13 & 5.96 & 34.14 & 7.21 & .34 & NS \\
\hline
\end{tabular}

Since no significant differences were found in social skills, additional analyses were performed to determine whether the same would hold true for communication skills. Between group comparisons were made, using the age equivalent scores of the Communication domain and the receptive and expressive language subdomains, and again, the results revealed no significant differences. The data and results of these analyses are presented in Table IX. 
TABLE IX

BETWEEN GROUP COMPARISONS OF COMMUNICATION DOMAIN AND SUBDOMAIN MEANS AND STANDARD DEVIATIONS OF DAY CARE AND NON-DAY CARE SUBJECTS

Day Care Non-Day Care $\underline{t} \quad \underline{p}<$

Domain/

Subdomain

Communication

Receptive

Expressive

(in mo.)

(SD)

38.25

$38.65(9.27)$

$36.75(6.82)$
Mean

(in mo.)

$(S D)$

$39.14 \quad(8.08) \quad .36 \quad$ NS

$38.93(11.39) \quad .70 \quad$ NS

$38.43 \quad(9.34) \quad .64 \quad$ NS

To summarize the results of the second question, it appears that spending a significant amount of time in day care does not affect communication or social skills of three year olds.

\section{DISCUSSION}

Results of this study indicated that 36 to 48 month old children who have a history of expressive language delay score significantly lower than normal subjects in the expressive skills and receptive skills subdomains and the communication and socialization domains of the vineland Adaptive Behavior scales. These results are consistent with those reported by spangle-Looney (1988) who found that two year old subjects identified as having expressive language delays also demonstrated both communication and socialization delays on this measure. The results also show that 
even though the expressive language delayed (ELD) group scored significantly higher in the communication domain at three years than at two years, the scores were still significantly lower than the normal group's scores. It can be concluded, then, that although children who have a history of expressive language delay are becoming more proficient in their use of language, they still demonstrate significant differences in their communication and socialization skills as a group.

In looking at the ELD group's individual scores, however, it appears that some of the group members can no longer be considered to be delayed in both receptive and expressive language, and social skills. Domain standard scores that are below 85 represent more than one standard deviation below the mean according to VABS criteria, and indicate a significant delay. Using this criterion, only $33 \%$ of the ELD subjects show a delay in the communication domain, and $37 \%$ show a delay in the socialization domain. It appears that although on the average, the ELD subjects score lower in all areas than the normal subjects, not all can still be considered delayed.

An important factor to note in terms of which subjects can still be considered delayed is membership in the subgroups formed in Spangle-Looney's (1988) study. Based on the data presented in Table VI, it appears that subjects who were classified as expressively delayed only are more likely 
to have communication and socialization skills that are adequate for their chronological age than subjects classified as expressively and receptively delayed. Therefore, it appears that children who have a history of expressive language delay without a concomitant receptive delay are more likely to develop age-appropriate communication and socialization skills than their expressive and receptively delayed counterparts.

Support for the above statement can be found in the results of a study by Beitchman, Hood, Rochon, and Peterson (1989). In looking at language impaired children, they found a correlation between degree of language impairment and being at risk for psychiatric impairment, namely behavior and emotional disorders. They found that children with more narrow language disorders (i.e., only one component of language that is delayed) were less likely to have an accompanying behavior or emotional disorder. Children with more general disorders (i.e., across two or more parameters) have a higher tendency to have associated behavior or emotional disorders. Beitchman et al. (1989) explain this by stating that more severely language delayed children probably have a general underlying immaturity compared to their peers, and therefore are not able to function as well in social situations.

The results of the day care portion of this study were consistent with claims made by both Belsky and steinberg 
(1978) and Rutter (1982), who reported that day care has neither positive nor negative effects on social skills. The fact that the communication and socialization skills of subjects who spend a significant amount of time in day care do not differ from subjects who do not spend a significant amount of time in day care could be comforting information for parents who are concerned that their children may be at a disadvantage by either attending or not attending day care.

However, it should be mentioned that this question was dealt with in a rather general way by this examiner, and the results should only be considered in that light. Several important factors were not investigated at in this study, and had they been included, the results may have been different. These factors include the length of time (i.e., months/years) the child had attended day care and the type of day care setting (i.e., curriculum based, or out of home care without educational enrichment). Also, the failure to find a difference between the two groups may have been due to the small number of subjects, which lessened the amount of power in the statistical tests. In order to have a better understanding of the effect of day care on social skills, more in-depth research needs to be done. 
CHAPTER V

SUMMARY AND IMPLICATIONS

SUMMARY

Language development in young children is a very complex process in which many skills are learned in a relatively short period of time. While children are learning to understand the structures that are being said to them, they are also learning how to produce their own words and sentences, as well as how to use their newly acquired communication skills as social tools. With such a vast amount of information to process, it is no wonder that some children are not as proficient in their understanding or use of communication skills as others of the same age. In fact, it has been shown by Spangle-Looney (1988) that children who have a history of expressive language delay also present a delay in their social skills as measured by the vineland Adaptive Behavior Scales (Sparrow, Balla, \& Cicchetti, 1984 ).

The purpose of this study was to compare receptive language, expressive language, and socialization skills of 36 to 46 month old children who were considered to have a history of an expressive language delay with normal children of the same age level. Two questions were addressed in this 
study. First, do children who at age two were considered to have an expressive language delay continue to demonstrate deficits in communication and socialization as measured on the Vineland Adaptive Behavior Scales (VABS) at three years of age? And second, within diagnostic groups, do children who spend a significant amount of time in day care show a difference in their social skills from children who do not spend a significant amount of time in day care?

The instrument that was utilized to collect the data for the first question was the Vineland Adaptive Behavior Scales (Sparrow, Balla, \& Cicchetti, 1984), which was presented to the parent of each subject in an interview fashion. Data collection for the day care section was conducted through the use of a questionnaire which was mailed to the parent of each subject.

The results of both questions were analyzed through use of two-tailed t-tests for unmatched groups. The results of the first question indicated that the scores of the Expressive Language Delayed (ELD) group, as a whole, were still significantly lower than the scores of the normal group in the receptive and expressive language subdomains and in the communication and socialization domains of the VABS. In comparing the groups over time, the results indicated that the communication skills of the ELD group improved significantly in the one year period, as measured by their standard score performance. Other within-group 
comparisons revealed stable performances in social skills for both groups over time. It was also determined that the ELD subjects who at age two had concomitant receptive delays were more likely to remain delayed in both communication and socialization than the ELD subjects who at age two were identified as having an expressive-only language delay.

The results of the day care analyses revealed that no significant difference existed in the socialization or communication skills of children who spend a significant amount of time in day care and of those who do not spend a significant amount of time in day care.

\section{CLINICAL IMPLICATIONS}

Results of this study show that children who were identified at 2 years of age as having an expressive language delay still score significantly lower at age 3 than their normal age mates in both communication and socialization domains of the VABS, even though they have become more proficient in their use of language. However, at 3 years of age, almost two-thirds of the children with a history of language delay demonstrated both communication and socialization skills that were adequate for their chronological age. This suggests that while the majority of young children who demonstrate difficulty with the language acquisition process before age three may just be "late bloomers", and will develop age-appropriate skills without 
additional intervention, a substantial proportion of this group continues to show deficits at age three.

Since as many as one-third of the children identified as having a language delay at two years still demonstrated delayed communication and socialization skills at age three, it is important that parents of very young children identified as having language delays be provided with instruction on enrichment strategies to create a facilitative environment for language learning in the home. This training may serve to enhance the language learning of the "late bloomers", as well as serve as added input for the children who are truly delayed.

Children who are still delayed in their communication skills at age three should be considered for outside intervention as well. Since it has been shown that delayed social skills often accompany delayed communication skills, focus of intervention should include emphasis on pragmatics as well as receptive and expressive language.

\section{RESEARCH IMPLICATIONS}

In order to support the above statement that the majority of children who are identified at 2 years of age as having a language delay develop age-appropriate communication and socialization skills without intervention, further research investigating the performance of these same children at age 4 must be conducted. Also, it would be 
beneficial to determine if whether or not the children who continue to demonstrate a language delay at age 3 still perform significantly lower than their normal age mates on tests of expressive language, receptive language, and socialization at age 4 . These findings would further substantiate the claim that early language intervention either through parent training or through clinical intervention - is justified for toddlers identified as having language delays. 


\section{REFERENCES}

Arwood, E.L. (1983). Pragmaticism. Rockville, MD: Aspen Systems Corporation.

Bates, E., \& MacWhinney, B. (1982). Functionalist approaches to grammar. In E. Wanner and L. Gleitman Eds.), Language acquisition: the state of the art. Cambridge: Cambridge University Press.

Beitchman, J.H., Hood, M.A., Rochon, J., \& Peterson, M. Empirical classification of speech/language impairment in children: II. behavioral characteristics. Journal of the American Academy of Child Adolescence and Psychiatry, 28, 118-123.

Bayley, N. (1969) . Bayley scales of infant development. New York: Psychological Corporation.

Belsky, J., \& Steinberg, L.D. (1978). The effects of day care: A critical review. Child Development, 49, 929949 .

Berko-Gleason, J. (1984). The development of language. Columbus, $\mathrm{OH}$ : Bell \& Howell Company.

Bloom, L. (1970). Language development: form and function in emerging grammars. Cambridge: The M.I.T. Press.

Bloom, L. (1974). Talking, understanding, and thinking. In R.L. Schiefelbusch and L.L. Lloyd (Eds.), Language perspectives - acquisition, retardation, and intervention. Baltimore: University Park Press.

Bloom, L., \& Lahey, M. (1978). Language development and language disorders. New York: John Wiley \& Sons.

Chapman, R.S. (1978). Comprehension strategies in children. In J.F. Kavanagh and W. Strange (Eds.), Speech and language in the laboratory, school, and clinic. Cambridge: M.I.T. Press.

Chapman, R.S. (1982). Issues in child language acquisition. In M.J. Lass, L.V. McReynolds, J.L. Northern, and D.E. Yoder (Eds.), Speech, Language and Hearing, Volume 1: Normal Processes. Philadelphia: W.B. Sanders Co. 
Chapman, R.S., \& Miller, J. (1975) . Word order in early two and three word utterances: does production precede comprehension? Journal of Speech and Hearing Research, 18, 355-371.

Eimas, P.D. (1974). Linguistic processing of young infants. In R.L. Schiefelbusch and L.L. Lloyd (Eds.), Language perspectives - acquisition, retardation, and intervention. Baltimore: University Park Press.

Fraser, C., Bellugi, u. , \& Brown, R. (1963) . Control of grammar in imitation, comprehension and production. Journal of Verbal Learning and Verbal Behavior, $\underline{2}$, 121-135.

Ingram, D. (1974). The relationship between comprehension and production. In R.L. Schieflbusch and L.L. Lloyd (Eds.), Language presepectives - acquisition, retardation and intervention. Baltimore: University Park Press.

Kaplan, E.L. \& Kaplan, G.L. (1970). The prelinguistic child. In J. Elliot (Ed.), Human development and cognitive processes. New York: Holt, Rinehart and Winston.

Klass, C.S. (1986). The autonomos child. Philadelphia: The Falmer Press.

Leonard, L.B., Bolders, J.G., \& Miller, J.A. (1976). An examination of the semantic relations reflected in the language usage of normal and language-disordered children. Journal of Speech and Hearing Research, 19, 371-392.

Mattison, R.E., Cantwell, D.P., \& Baker, L. (1980). Behavior Problems in children with speech and language retardation. Child Psychiatry and Human Development, $10(4), 246-257$.

Menyuk, P. (1974) - Early development of receptive language: from babbling to words. In R.L. Schiefelbusch and L.L. Lloyd (Eds.), Language perspectives - acquisition, retardation and intervention. Baltimore: University Park Press.

Meyers, J.K. \& Bean, L.L. (1968). A decade later: a follow-up of social class and mental illness. New York: Wiley \& Sons.

Miller, J. (1981). Assessing language production in children. Austin, TX: Pro-Ed. 
Moore, T. (1964). Children of full-time and part-time mothers. Cited in J. Belsky and L.D. Steinberg (1978) The effects of day care: A critical review. child Development, 49 , 929-949.

Nelson, K. (1973). Structure and strategy in learning to talk. Monographs of the society for Research in Child Development, $\underline{38}$.

Paul, R., Fischer, M.L., \& Cohen, D.J. (1988). Sentence comprehension strategies in children with autism and developmental language disorders. Journal of Autism and Developmental Disorders, 18, 669-680.

Paul, R. \& Spangle-Looney, S. (1987). Communication and socialization profiles in expressive language delayed toddlers. A paper presented at the annual conference of the American Speech and Hearing Association. New orleans.

Prutting, C. (1982). Social competence. Journal of Speech and hearing Disorders, 47, 123-134.

Reed, V. (1986). An introduction to children with language disorders. New York: Macmillan Publishing Co.

Roth, F.P., \& Clark, D.M. (1987). Symbolic play and social participation abilities of language-impaired and normally developing children. Journal of Speech and Hearing Disorders, 52, 17-29.

Rutter, M. (1982). Social-emotional consequesnces of day care for preschool children. In E.F. Zigler and E.W. Gordon (Eds.) Day Care: Scientific and social policy issues. Boston: Auburn House Publishing Company.

Schwartz, J., Strickland, R. \& Krolick, G. (1974). Infant day care: behavioral effects at preschool age. Developmental Psychology, 10, 502-506.

Scoville, R. (1983). Development of the intention to communicate: the eyes of the beholder. In $L$. Feagans, C. Garvey, and R. Golinkoff (Eds.), The origins and growth of communication. Norwood, NJ: Ablex.

Spangle-Looney, S. (1988). Communication and socialization profiles in toddlers with expressive language delay. A Masters Thesis of Portland State University, Portland, oregon. 
Sparrow, S.S., Balla, D.A., \& Cicchetti, D.V. (1984).

Vineland Adaptive Behavior Scales. Circle Pines, MN:

American Guidance Service.

Snow, C., Midkiff-Borunda, S., Small, A., \& Proctor, A. (1984). Therapy as social interaction: analyzing the contexts for language remediation. Topics in Language Disorders, $4(4), 72-84$.

Terman, L. \& Merrill, M. (1960). Stanford-Binet Intelligence Scale. Boston: Houghton Mifflin.

Thal, D., \& Bates, E. (1988). Language and gestures in late talkers. Journal of Speech and Hearing Research, 31, 115-123.

Vygotsky, L.S. (1962). Thought and language. Cambridge: M.I.T. Press. 
APPENDIX A

LETTER OF INFORMED CONSENT 
I, , hereby agree to

serve as a subject in the research project on language development in young children conducted by Rhea Paul.

I understand that the study involves seeing my child yearly for speech and language evaluation and wideotaping conversations between me and my child. I understand that these tapes will be transcribed for analysis of my child's spoken language patterns.

It has been explained to me that the purpose of the study is to learn whether children who begin talking late are at risk for later learning problems.

I may not receive any direct benefit from participation in this study, but my participation may help to increase knowledge which may benefit others in the future.

Dr. Paul has offered to answer any questions I may have about the study and what is expected of me in the study. I have been assured that all information I give will be kept confidential and that the identity of all subjects will remain anonymous.

I understand that I am free to withdraw from participation in this study at any time without jeopardizing my relationship with Portland State University.

I have read and understand the foregoing information. 
APPENDIX B

HUMAN SUBJECT APPROVAL 


\section{Portland State University}

\section{MEAORA.NDIN}

HUSAN SUBJECTS RESEARCH REVIEW COMITTEE $1987-88$

-DATE: 3 May 1988

TO: Rhea Paul, SP

FROY: Robert C. Holloway, Chairperson

Human Subjects Research Review Cominittee (HSRRC)

RE: HSRRC Approval

In accordance with your request, the Human Subjects Research Review Committee has reviewed your proposal entitled Late Bloomers?

Communication Skills in Non-Speaker Toddlers: Follow-up Study for compliance with DHHS policies and regulations on the protection of human subjects.

The committee is satisfied that your provisions for protecting the rights and welfare of all subjects participating in the research are adequate and therefore the project is approved.

c: Office of Grants and Contracts

RCH: asm 


\author{
APPENDIX C \\ VINELAND ADAPTIVE BEHAVIOR SCALES \\ COMMUNICATION AND SOCIALIZATION \\ DOMAINS
}


<1. Turns gyes and head toward sound

2 Yes. usually

ITEM

SCOAES

No never

No opportunity

OK Don i know

2. Listens at least momentarliy when spoken to by caregiver.

3. Smiles in response to presence of caregiver

4. Smiles in response to presence of familiar person other than caregiver.

5. Raises arms when caregiver says. "Come here" or "UD"

6. Demonstrates understanding of the meaning of "no

7. Imitates sounds of adults immediately after hearing them.

8. Demonstrates understanding of the meaning of at least 10 words.

1 9. Gestures appropriately to indicate "yes," "no." and "I want."

10. Listens attentively to instructions.

11. Demonstrates understanding of the meaning of "yes" or "okay."

12. Follows instructions requiring an action and an object.

13. Points accurately to at least one major body part when asked.

14. Uses first names or nicknames of siblings, friends. or peers. or states their names when asked.

15. Uses phrases containing a noun and a verb. or two nouns.

16. Names at least 20 familiar objects without being asked. DO NOT SCORE 1 .

17. Listens 10 a story for at least five minutes

18. Indicates preference when offered a choice.

219. Says at least 50 recognizable words. DO NOT SCORE 1

20. Spontaneousiy relates experiences in simple terms.

21. Delivers a simple message.

22. Uses sentences of four or more words

23. Points accurately to all body parts when asked. DO NOT SCORE 1

24. Says at least 100 recognizable words DO NOT SCOFE

25. Speaks in full sentences.

26. Uses " $a$ " and "the" in phrases or sentences.

27. Follows instructions in "if-then" form

28. States own first and last name when asked

29. Asks questions beginning with "what." "where." "who." "why." and "when." DO NOT SCORE 1

1.4 30. States which of two objects not present is bigger

31. Relates experiences in detail when asked

32. Uses either "behind" or "between" as a preposition in a phrase.

33. Uses "around" as a preposition in a phrase.

Count items before basal as 2 , items after ceiling as 0 .

COSA:SN:

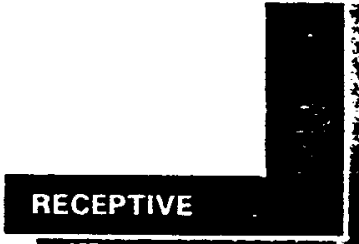

Sum of 2s, is, Os page 2 
$\begin{array}{rll} & 2 & \text { Yes. Usually } \\ \text { mEM } & \text { f } & \text { Sometimes or partially } \\ \text { sconts } & \text { No. never } \\ & \text { No No Opportunity } \\ & \text { DK Don't know }\end{array}$

34. Uses phrases or sentences containing "but" and "or."

35. Articulates clearly, witnout sound substitutions

36. Talls popular story. fairy tale. lengthy joke. or television show plot

37. Recites all letters of the alphabet from memory.

38. Aeads at least three common signs.

39. States month and day of birthday when asked

40. Uses irregular plurals.

- 41. Prints or writes own first and last name.

42. States telephone number when asked. N MAY BE SCORED

43. States complete home address, including city and state. when asked.

44. Reads at least 10 words silently or aloud

45. Printe or writes at least 10 words from memory.

46. Expresses ideas in more than one way, without assistance.

47. Reads simple stories aloud.

1. 48. Prints or writes simple sentences of three of lour words

49. Attends to school or public lecture more than 15 minutes

50. Reads on own initiative.

51. Reads books of at least second-grade level.

52. Arranges items or words alphabetically by first letter.

53. Prints or writes short notes or messages.

- 54. Gives complex directions to others.

55. Writes beginning letters. DO NOT SCORE 1 .

56. Reads books of at least fourth-grade level.

57. Writes in cursive most of the time. DO NOT SCORE

10458 . Uses a dictionary.

59. Uses the table of contents in reading materials.

60 . Writes reports or compositions. DO NOT SCORE 1.

61. Addresses envelopes completely.

62. Uses the index in reading materials.

63. Reads adult newspaper stories. N MAY BE SCOAED

64. Has realistic long-range goals and describes in detail plans to achieve them.

65. Writes advanced letters.

66. Reads adult newspaper or magazine stories each week N MAY BE SCORED

67. Writes business leiters. DO NOT SCOAE 1

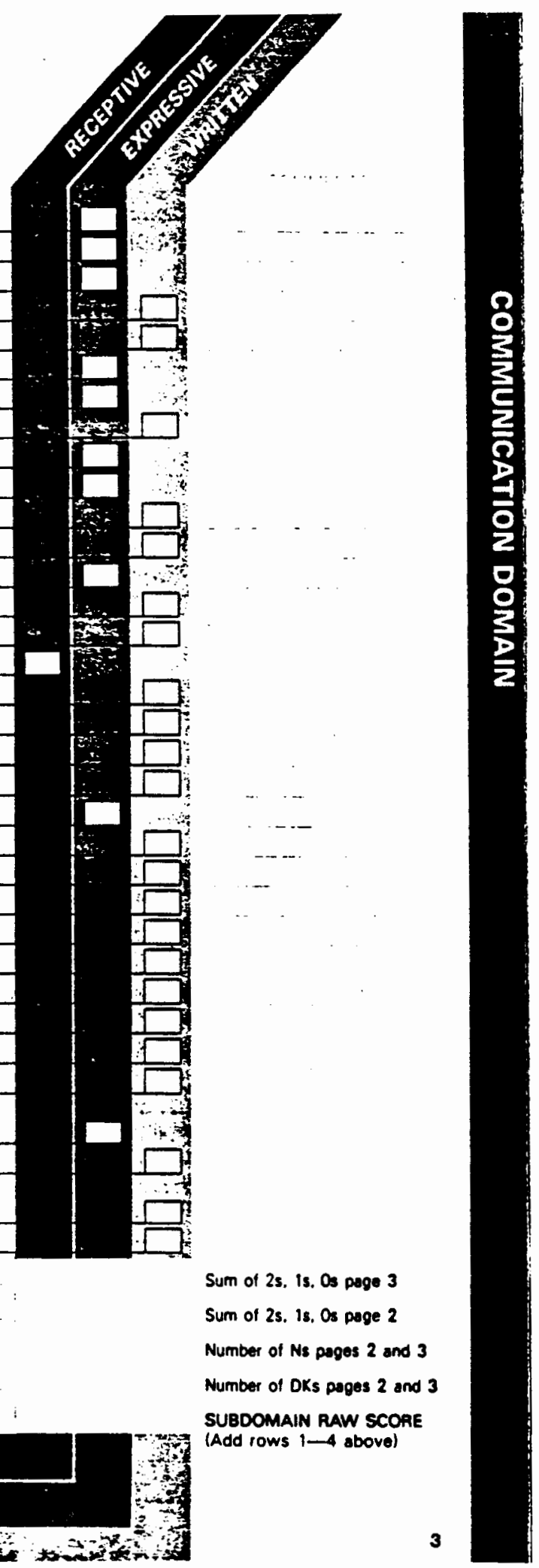

RECEPTIVE

EXPRESSIVE

Grivite?

Sum of 2s. 1s, Os poge 2

Ne pages 2 and 3

SUBDOMAIN RAW SCOR

(add rows 1-4 sovel 


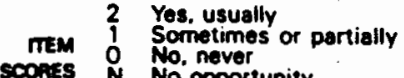

$$
\begin{aligned}
& \text { NK Do opportunity }
\end{aligned}
$$

c1 t. Looks at face of caregiver.

2. Responds to voice of caregiver or another person.

3. Distinguishes caregiver from others.

4. Shows interest in novel objects or new people.

5. Expresses two or more recognizable emotions such as pleasure, sadness, fear, or distress.

6. Shows anticipation of being picked up by caregiver.

7. Shows affection toward familiar people.

8. Shows interest in children or peers other than siblings.

9. Reaches for familiar person.

10. Plays with toy or other object alone or with others.

11. Plays very simple interaction games with others.

12. Uses common household objects for play.

13. Shows interest in ectivities of others.

14. Imitates simple adult movernents, such as clapping hands or waving good-bye, in response to a model.

15. Laughs or smiles appropriately in response to positive statements.

16. Addresses at least two familiar people by name.

17. Shows desire to please caregiver

18. Participates in at least one game or activity with others.

19. Imitates a relatively complex task several hours after it was performed by another.

20. Imitates adult phrases heard on previous occasions.

21. Engeges in elaborate make-believe activities, alone or with others.

- 22. Shows a preference for some friends over others.

23. Says "please" when asking for something.

24. Lobels happiness, sadness, fear, and anger in self.

25. Identifies people by characteristics other than name. when asked.

- 26. Sheres toys or possessions without being told to do so.

27. Names one or more favorite television programs when asked. and tells on what days and channels the programs are shown. N MAY BE SCORED.

28. Follows rules in simple games without being reminded.

29. Has a preferred friend of either sex.

30. Follows school or tacility rules.

- 31. Responds verbelly and positively to good fortune of others.

32. Apologizes for unintentional mistakes.

33. Has a group of friends.

34. Follows community rules.

- 35. Plays more than one board or cerd game requiring skill and decision making.

36. Ooes not talk with food in mouth.

37. Has a best friend of the same sex.

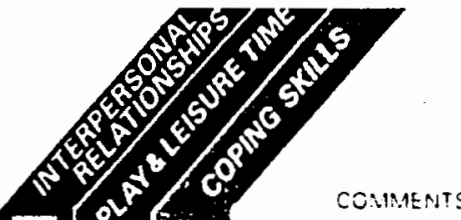

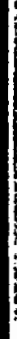
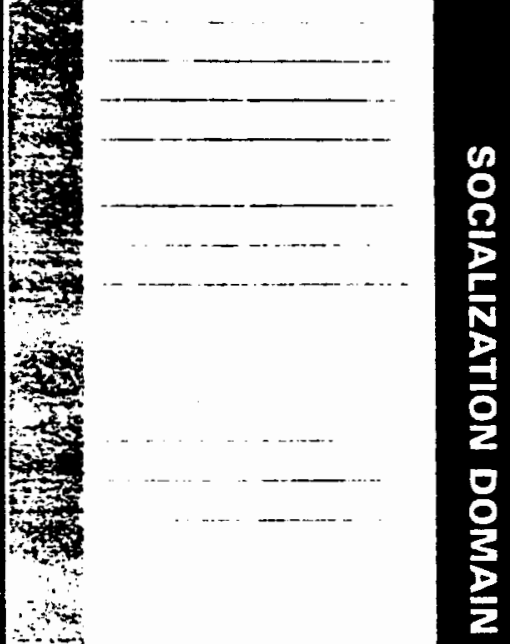

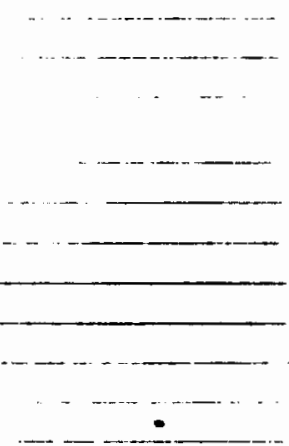

Count items before basal as 2. items after ceiling as 0

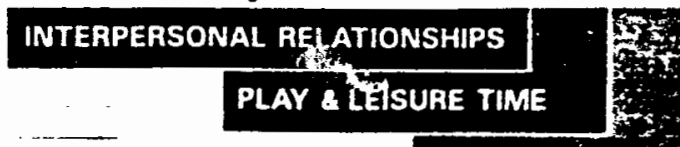

Sum of 2s, is, Os page 7 


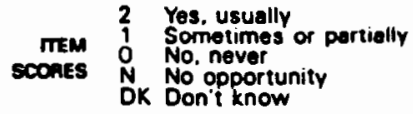

38. Responds appropriately when introduced to strangers.

7. 39. Makes or buys small gifts for caregiver or family member on major holidays. On own initiative.

40. Keeps secrets or confidences for more then one day.

41. Returns borrowed toys. possessions, or money to peers, or returns borrowed books to library.

42. Ends conversations appropriately.

- 43. Follows time limits set by ceregiver.

44. Refrains from asking questions or making statements that might embarrass or hurt others.

45. Controls anger or hurt feelings when denied own way.

46. Keeps secrets or confidences for as long as appropriate

19.11 47. Uses appropriate table manners without being told. DO NOT SCORE 1.

48. Watches television or listens to radio for informetion about : perticular area of interest. N MAY BE SCORED.

49. Goes to evening school or focility events with friends, when accompanied by an adult. N MAY BE SCORED

50. Independently meighs consequences of ections before making docisions.

51. Apologizes for mistakes or errors in judgment.

12. 52 . Remembers binthdays of anniversaries of immediate family members 14. and special friends.

53. Initiates conversations on topics of particular interest to others.

54. Has a hobby.

55. Repays money borrowed from caregiver.

$10+56$. Responds to hints or indirect cues in conversation.

57. Participates in nonschool sports. N MAY BE SCORED

58. Wetches television or listens to radio for practical, day-to-day information. N MAY BE SCOAED

59. Makes and keeps appointments.

60. Watches television or liatens to radio for newrs indepandently. N MAY BE SCORED.

61. Goes to evening school or facitity events with friends. without adult supervision. N MAY BE SCORED

62. Goes to evening nonschool or nonfacility events with friends, without adult suparvision.

63. Belongs to older adolescent organized club, interest group. or social or service organization

64. Goes with one persen of opposite sex to party or public event where many people are present.

65. Goes on double or triple dates.

66. Goes on single dates.

Count items before besel as 2. rems after ceiling as 0 .

1.

2.

3.

4.

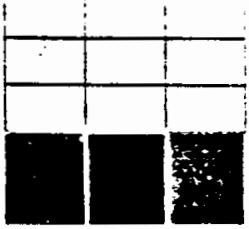

Sum of 2s. Is, 0 pape 8

Sum of 2s. 1s. Os page 7

Number of Ns pages 7 and 8

Number of DKs pages 7 and 8

SUBDOMAN RAW SCONE

(Add rows $1-4$ above) 
APPENDIX D

DAY CARE QUESTIONNAIRE 


\section{Portland State University}

P. (). Bux 751, Pintund. ()R $97317-17751$

Dear Parenls.

As you knod, wre are trying to learn as much as de can abuu? children's language development and what influences it. One question we have concerns the effect of out-of-home care on children's speech. Te wondered whether you would be willing to let us know about your child's out-or-home care experiences. As with all parts of this study, you may refuse to participate in this portion. and if you chose to participale. you may withdraw at any time. Your decision whether or not to tatie part in this: segment will in no way affect your participation in any other part of the study. or any services you receive at Portland State liniversity.

If you are willing to participate. please fill out the questionnaire below and return it in the enclosed stamped envelope to: Pam Dahm. Speech and Hearing Sciences, Portland State University. P.0. Box 751. Portland 97207. Please feel free to call Pam at $464-35 j 3$ if you have any questions ai all. Thank you in advance for your help.

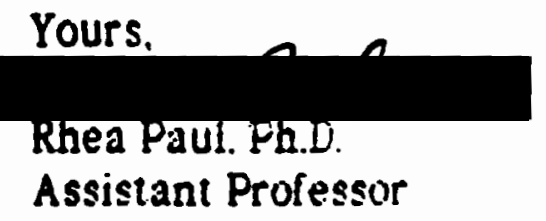

Child's name

Birthdate

Hours per week spent in out-of-home childcare

Type of care (check onei: home daycare with another mom daycare cenier

Number of children in your child's group or class 